\title{
A Rapid Quantitative Real-Time PCR-Based DNA Quantification Assay Coupled with Species - Assignment Capabilities for Two Hybridizing Macaca Species
}

\author{
A. Barr A. Premasuthan J. Satkoski D.G. Smith D. George \\ S. Kanthaswamy \\ University of California, Davis, Calif., USA
}

\section{Key Words}

Species identification $\cdot$ Rhesus macaques $\cdot$ Macaca mulatta $\cdot$ Long-tailed macaques - Macaca fascicularis - DNA quantification - TaqMan ${ }^{\mathrm{TM}}$ assay

\begin{abstract}
Regional populations of rhesus and long-tailed macaques exhibit fundamental differences in mitochondrial DNA, short tandem repeat and single nucleotide polymorphism variation between mainland and insular Southeast Asian populations. Some studies have revealed genetic admixture between these species due to natural hybridization and human-assisted intercrosses. A quantitative real-time PCR (qPCR) assay was developed to efficiently determine the species of origin of a macaque biological sample, and to quantify the species-specific template DNA. Prior knowledge of species identity and DNA concentrations are crucial for maintaining cost-effective methods and accurate DNA analysis. DNA from 109 regionally representative rhesus and long-tailed macaques was qPCR amplified to determine the species and template quantities. Of the 19 Vietnamese long-tailed macaques, 3 samples were discovered to be hybrids.
\end{abstract}

Copyright $\odot 2011$ S. Karger AG, Basel

\section{Introduction}

Rhesus (Macaca mulatta) and long-tailed (M. fascicularis) macaques are the most and second most commonly used non-human primate models for biomedical research of human diseases [Gibbs et al., 2007]. Rhesus macaques are distributed from eastern Afghanistan to northeastern China, and long-tailed macaques are distributed to the south of the rhesus range including continental and insular Southeast Asia (fig. 1). The range of M. fascicularis extends across 30 degrees of latitude and 35 degrees of longitude, covering southern Bangladesh and southern Burma, the southern

\section{KARGER}

(C) 2011 S. Karger AG, Basel

Fax +41613061234

E-Mail karger@karger.ch Accessible online at: www.karger.com www.karger.com/fpr
Dr. Sree Kanthaswamy

Department of Anthropology, University of California One Shields Avenue, Davis, CA 95616 (USA)

Tel. +1 5307521588

E-Mail skanthaswamy@ucdavis.edu 


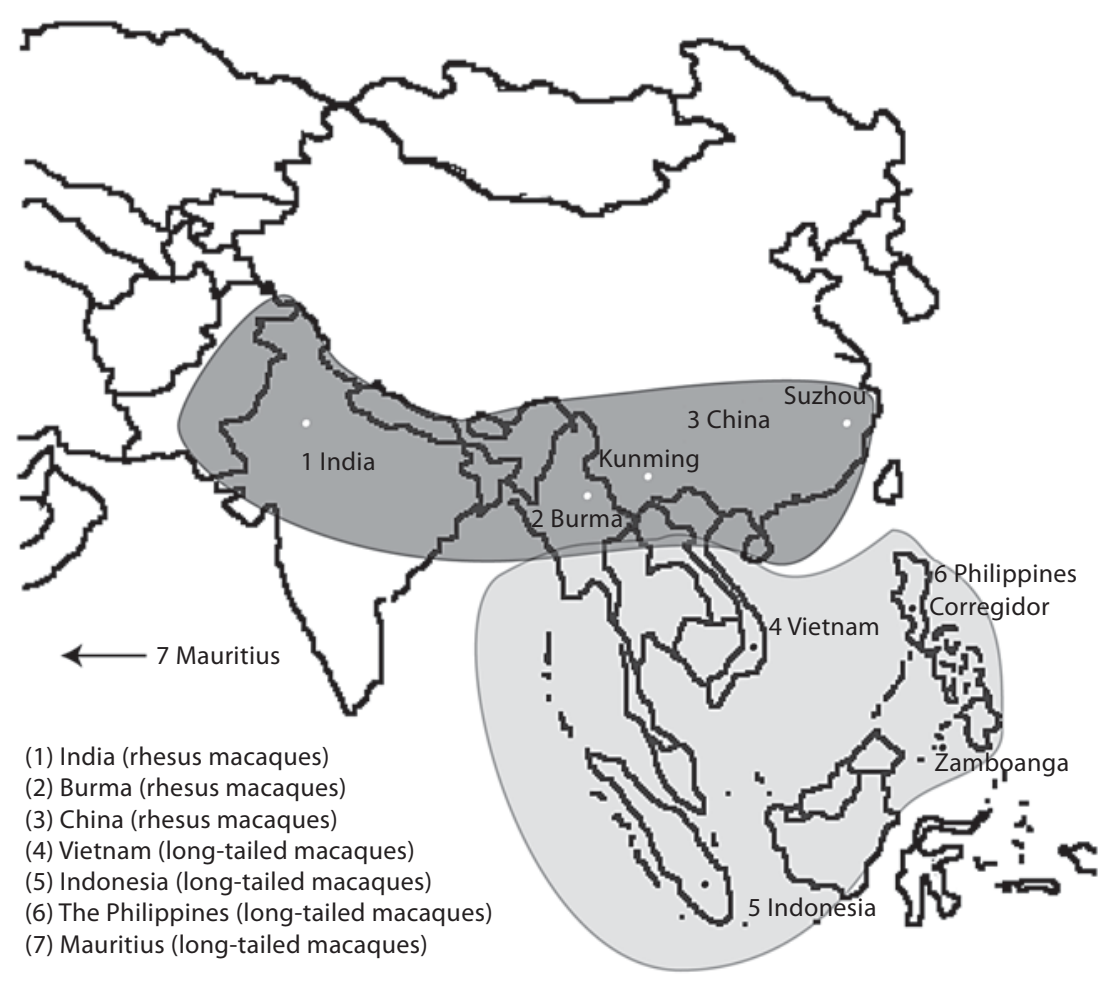

Fig. 1. Geographic ranges and sampling sites of rhesus (dark gray) and long-tailed macaques (light gray) [Kanthaswamy et al., 2008].

part of the Indochinese peninsula, the Isthmus of Kra, the Malay Peninsula, Sumatra, Borneo, Java, and the Lesser Sunda Islands as far east as Timor, the Philippine Islands, and many small nearby islands, including the 3 southernmost Nicobar Islands [Fooden, 1995]. As figure 1 shows, both macaque species are parapatric in a small portion of northern Indochina and are marginally sympatric in the west-central region of Thailand, southern Laos, and central Vietnam [Ferguson et al., 2007], and primatologists have long suspected natural hybridization between these two species in areas where they co-occur [Fooden, 2000; Hamada et al., 2006; Tosi and Coke, 2007; Malaivijitnond et al., 2008; Bonhomme et al., 2009]. Long-tailed macaques in Indochina may have undergone significant hybridization with rhesus macaques during Pleistocene fluctuations of the boundary between these two populations, causing significant inflow of rhesus genes into the long-tailed macaque genome. Based on a study of Y chromosome and mitochondrial DNA (mtDNA) markers in long-tailed macaques, Tosi et al. [2002] have proposed that introgression from male rhesus to female long-tailed macaques was one conduit for gene flow. Consequently, Indochinese long-tailed macaques exhibit much greater genetic diversity than long-tailed macaques from other geographic locations [Kanthaswamy et al., 2008, 2010]. 
The broad geographic distribution of these two species over complex terrain leads to an expectation of significant genetic and phenotypic variability between and within these macaque species, especially those originating from disparate geographic regions, that would complicate their use interchangeably during experimentation. Recent research has also demonstrated stark genetic differences between two regional varieties of rhesus macaques, i.e., the Indian- and Chinese-origin rhesus macaques [Smith et al., 2006; Ferguson et al., 2007; Kanthaswamy et al., 2008]. Due to their high level of divergence [Ferguson et al., 2007; Hernandez et al., 2007; Tosi and Coke, 2007], samples from these two varieties can produce varying responses to the same research protocol [Kanthaswamy et al., 2008]. The same is true for geographically separated long-tailed macaques [Tosi and Coke, 2007]. Yet there is ample evidence that some of the animals, especially rhesus macaques of Chinese origin, which have been purchased and/or bred in captivity for biomedical experimentation in the US, exhibit recent and ancient genetic signatures of interspecific admixture [Kanthaswamy et al., 2010]. The same is true for long-tailed macaques [Kanthaswamy et al., $2008,2010]$. Sixty-five percent of all long-tailed macaques imported into the US are from Chinese breeders, who in turn have obtained their wild-caught founder stocks from Indonesia, Malaysia, the Philippines and Indochina including Cambodia, Laos and Vietnam [AESOP Project, 2006]. Obtaining animals from the wild for biomedical research can result in the inadvertent inclusion of animals of different or hybrid ancestry and this can confound interpretations of phenotypic variance, especially among traits that are governed by high levels of additive genetic variance [Falconer, 1960]. In order to decrease genetic variability among study animals, it is important for biomedical researchers to use research stocks whose species of origin is known and that are relatively genetically homogeneous. By reducing the amount of genetic variability among their experimental animals, both the variability in test results and the number of animals required for research will decrease.

In order to confirm a priori the species from which a biological sample has been drawn, a rapid, accurate and inexpensive DNA-based assay is of particular importance to the biomedical research community by which the sample, found in the wild or obtained from primate product distributors, including primate research centers, may be tested. This assay will also benefit captive breeding programs in zoos and wildlife rehabilitation centers that need to identify possible hybrid animals in their breeding stocks. DNA-based methods for macaque species testing have usually relied on mtDNA for several reasons including their high copy numbers and protein coats that protect against degradation and environmental challenge. Typically, mtDNAbased methods rely on the amplification of a section of a gene, for example, cytochrome b, cytochrome oxidase subunit 1 or the hypervariable region 1 . The amplicon is then sequenced directly and the DNA sequence is compared to sequences in a database. Because of its capability to discriminate species, the cytochrome oxidase subunit 1 gene has been utilized in the barcoding of animal species [Hajibabaei et al., 2007]. mtDNA genes can reveal some intraspecific differences including the separation of most regional populations of rhesus and long-tailed macaques and contain sufficient interspecies variation to facilitate species determination of a particular sample [Smith and McDonough, 2005]. However, mtDNA is maternally inherited and can neither detect male-mediated gene flow [Kanthaswamy and Smith, 2004; Hajibabaei et al., 2007], nor be used to quantify the nuclear DNA on which most of the biomedically relevant protein-coding genes reside. Short tandem repeat (STR) 
[Ferguson et al., 2007] and single nucleotide polymorphism (SNP)-based procedures have been developed [Kanthaswamy et al., 2008, 2010] that ascertain evolutionary relationships among groups of animals from the same species or groups from different species among populations of rhesus and long-tail macaques. While these assays can provide the discriminatory power to separate species and detect intraspecies variation, they rely on complicated multiplex approaches that are cumbersome and costly. An efficient assay would facilitate the unequivocal determination of the species of origin, including interspecies hybrids, of a sample that may sometimes be in minuscule quantities, and quantify the species-specific template DNA in picogram amounts (especially with the increasingly frequent use of these species as subjects in studies involving stem cells, where detection of one or two molecules of nuclear DNA has to be robust) prior to downstream research which is important for maintaining cost-effective methods and accurate DNA analysis. Therefore, the goals of this project are twofold: the first goal is to develop a quick, sensitive, and accurate protocol to identify the species to which a particular biological macaque sample belongs, and the second goal is to ensure that DNA extracted from these rhesus and long-tail macaque samples can be accurately quantified. This study was designed to exploit the beneficial qualities of real-time or quantitative PCR (qPCR) and TaqMan ${ }^{\mathrm{TM}}$ technology to rapidly and accurately determine the species and quantity of a biological macaque sample [Evans et al., 2007]. Nuclear DNA quantification of human samples is routinely performed to optimize the PCR of multiplexed STR markers [Ferguson et al., 2007]. Adjusting template DNA concentration based on quantification data prior to PCR analysis can be cost-effective and provides better quality control. For instance, extracted material that exhibits scant or no macaque DNA upon quantification could be set aside in favor of analyzing samples containing more DNA.

The candidate locus chosen for this study is a 704-bp fragment located on the macaque chromosome 11 [Degenhardt et al., 2009]. The Stat6 gene (signal transducer and activator of transcription 6) encodes a protein that is a member of the STAT family of transcription factors [Hou et al., 1994; Leek et al., 1997]. This protein is a key player in the regulation of antiapoptotic activity [Wurster et al., 2002]. Stat6 was considered an optimal candidate for the assay because it contains numerous SNPs that could be used to differentiate long-tailed from rhesus samples. Additionally, because the Stat6 locus is present in a single copy per haploid macaque genome [Degenhardt et al., 2009], an assay using this candidate marker could ensure effective species-specific quantification analysis of rhesus and long-tailed macaque DNA. It was important to target a single-copy gene because regions that have multiple genomic copies may allow the quantification of a fraction of a single cell's DNA but can lead to sequence variation within an individual and variable copy numbers across individuals affecting the accuracy of DNA quantification results.

\section{Materials and Methods}

This study was conducted on 109 whole blood samples obtained from the facilities listed in Kanthaswamy et al. [2008, 2010]. Blood samples of long-tailed macaques from each of the following locations (and number of samples or $n$ ) were used (fig. 1): Indonesia $(n=18)$, the Philippines, including samples from Corregidor and Zamboanga $(\mathrm{n}=17)$, Mauritius $(\mathrm{n}=16)$, and Vietnam $(n=19)$. Samples of rhesus macaques from India $(n=16)$, Burma $(n=5)$, and from Kunming and Suzhou $(\mathrm{n}=18)$ in China were also extracted (fig. 1). The 19 Vietnamese long- 
Table 1. Primers and probes used for PCR and qPCR optimization

\begin{tabular}{ll}
\hline Name & Sequence \\
\hline Forward Stat6 sequencing primer & $5^{\prime}$-AGACACATTTACACTAGAGG-3' \\
\hline Reverse Stat6 sequencing primer & $5^{\prime}$-TCTTTCTTTTCAGATTGTGTA-3' \\
\hline Forward Stat6 TaqMan primer & $5^{\prime}$-CCCAAGTGGGTCCAAGTGGCT-3' \\
\hline Reverse Stat6 TaqMan primer & $5^{\prime}$-GGATAGGGCAACAGAGAAGAT-3' \\
\hline Long-tailed Stat6 TaqMan probe & $5^{\prime}$-CTCCAGTGTATGAAGGGGCCCTGC-3' \\
\hline Rhesus Stat6 TaqMan probe & $5^{\prime}$-CTCCAGTGTATGAAGGAGCCCTGC-3' \\
\hline
\end{tabular}

List of all primers and probes used for PCR and qPCR optimization. The forward Stat6 TaqMan primer begins ( $\left.5^{\prime}\right)$ at base pair 371 and ends at base pair 391 (20 bp). The reverse Stat6 TaqMan primer begins at base pair 507 and ends at base pair $527(20 \mathrm{bp})$. Each probe begins at base pair 476 and ends at base pair 499 (23 bp).

tailed samples had not been previously tested with mtDNA or STRs to confirm that they were not interspecific hybrids.

DNA was extracted from the samples using the QIAGEN blood extraction kit according to the manufacturer's protocol (QIAGEN Inc., Valencia, Calif., USA). After isolating total DNA, amplification of the Stat6 gene was carried out using primers (table 1) designed from National Center for Biotechnology Information (NCBI; www.ncbi.nlm.nih.gov) GenBank entry accession number BV166781. Each PCR amplification consisted of $1.25 \mu \mathrm{l}$ of DNA extract, $0.25 \mu \mathrm{l}$ of each primer $(10 \mu \mathrm{M}), 0.85 \mu \mathrm{l}$ of $\mathrm{MgCl}_{2}(25 \mathrm{mM}), 0.25 \mu \mathrm{l}$ of each dNTP $(10 \mu \mathrm{M}), 1.25 \mu \mathrm{l}$ of buffer solution (BioLine $10 \times \mathrm{NH} 4$ reaction buffer without $\mathrm{MgCl}_{2}$; Tauton, Mass., USA), and $0.06 \mu \mathrm{l}$ of Taq polymerase (Invitrogen Platinum Taq DNA Polymerase, Carlsbad, Calif., USA; 5 U/ $\mu \mathrm{l}$ )

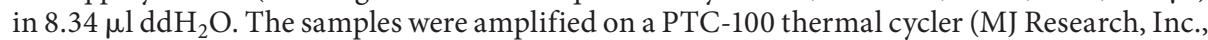
Waltham, Mass., USA). Cycle parameters were $3 \mathrm{~min}$ at $94^{\circ} \mathrm{C}$ followed by 45 cycles of $94^{\circ} \mathrm{C}$ for $30 \mathrm{~s}, 55^{\circ} \mathrm{C}$ for $30 \mathrm{~s}$, and $72^{\circ} \mathrm{C}$ for $45 \mathrm{~s}$, a final extension time of $5 \mathrm{~min}$ at $72^{\circ} \mathrm{C}$ and then a $4{ }^{\circ} \mathrm{C}$ final hold. After amplification, the PCR products $(3 \mu \mathrm{l} /$ well) were run alongside a 1-kb ladder on a $1.5 \%$ agarose gel containing $1.5 \mu \mathrm{l}$ of ethidium bromide for approximately $8 \mathrm{~min}$. The gels were then examined under UV light to ensure desired quantity and specificity were obtained.

To screen for heterozygotes, 6 samples from each sampling location were cloned using the QIAGEN PCR Cloning Kit according to the manufacturer's protocol (QIAGEN). Upon sequencing the cloned products, no heterozygotes were detected and we continued with direct sequencing of the remaining samples. The excess primers and dNTPs present in the post-PCR product were eliminated using ExoSAP-IT (Affymetrix, Santa Clara, Calif., USA); $5 \mu$ l PCR product and $2 \mu \mathrm{l}$ ExoSAP-IT were combined and incubated at $37^{\circ} \mathrm{C}$ for $15 \mathrm{~min}$ and then heated at $80^{\circ} \mathrm{C}$ for 15 min using the PTC-100 thermal cycler.

To make sets of forward and reverse strands for each sample a BigDye Terminator (Applied Biosystems, Foster City, Calif., USA) reaction was then set up using $1 \mu l$ ExoSAP-IT PCR product, $3.2 \mu \mathrm{l}(1 \mu \mathrm{M})$ of each primer, $1 \mu \mathrm{l}$ of BigDye Terminator v3.1 Ready Reaction Premix (Applied Biosystems), $2 \mu$ l of $5 \times$ BigDye Sequencing Buffer (Applied Biosystems), and $12.8 \mu 1$ $\mathrm{ddH}_{2} \mathrm{O}$ to make a total reaction volume of $20 \mu \mathrm{l}$. The cycle parameters were 25 cycles of $95^{\circ} \mathrm{C}$ for $20 \mathrm{~s}, 50^{\circ} \mathrm{C}$ for $10 \mathrm{~s}, 60^{\circ} \mathrm{C}$ for $4 \mathrm{~min}$, followed by a $4^{\circ} \mathrm{C}$ hold.

The unincorporated dyes were removed using the BigDye XTerminator Purification Kit (Applied Biosystems) according to the manufacturer's protocol. The sample mixture was subjected to electrophoresis on an ABI 3130 Genetic Analyzer (Applied Biosystems) using the BigDye XTerminator run module and POP7 polymer (Applied Biosystems). Forward and reverse sequences generated were then edited and aligned using Sequencher 4.9 (Gene Codes Corporation, Ann Arbor, Mich., USA). The resulting 48 consensus sequences (GenBank accession num- 
Portion of long-tailed Stat 6 amplicon:

Portion of rhesus Stat6 amplicon:

Long-tailed TaqMan probe sequence:

Rhesus TaqMan probe sequence:

Fig. 2. Species-specific TaqMan probe design. The long-tailed probe was labeled with a VIC reporter dye denoted in black and the rhesus probe was labeled with an FAM reporter dye denoted in gray (pink in the online version).

bers: JF422670-JF422717) were then aligned with samples of each specific geographic origin. During this step, any variation within a geographic subgroup was masked. Consensus sequences were created containing only invariable sites for that geographic population. The long-tailed and rhesus sequences were aligned separately to identify any intraspecific variation and to generate a single long-tailed and a single rhesus consensus sequence, respectively. These consensus sequences were monomorphic within each species. The long-tailed and rhesus consensus sequences were then aligned to find interspecific SNP(s). A single species-specific SNP was discovered (fig. 2). Two TaqMan probes (Applied Biosystems) that span the SNP site and flanking primer sequences were designed using PrimerBlast (http://www.ncbi.nlm.nih.gov/tools/ primer-blast/) (table 1). All sites of interspecific sequence disagreements were avoided in designing species-specific probes. Two probes were designed: one specific to all rhesus macaque samples and the second specific to all long-tailed samples. The rhesus macaque probe was labeled with an FAM reporter dye at the $5^{\prime}$-end and a quencher dye at the 3 '-end (Applied Biosystems). The long-tailed macaque probe was labeled with a VIC reporter dye at the $5^{\prime}$-end and a quencher dye at the $3^{\prime}$-end (Applied Biosystems). New primers (sequences) were designed to amplify a shorter sequence, thereby increasing the sensitivity of the assay.

To test for species specificity, the qPCR mixture was prepared with TaqMan ${ }^{\mathrm{TM}}$ Universal PCR Master Mix, forward and reverse primer mix (25 $\mu \mathrm{M}$ forward and reverse primers), $10 \mu \mathrm{M}$ rhesus-specific and long-tailed-specific probes, $20 \mathrm{ng}$ DNA and sufficient distilled water to yield a final volume of $12.5 \mu \mathrm{l}$. The real-time qPCR parameters were 1 cycle of $50^{\circ} \mathrm{C}$ for $2 \mathrm{~min}$ followed by $1 \mathrm{cycle}$ of $95^{\circ} \mathrm{C}$ for $10 \mathrm{~min}, 45$ cycles of $95^{\circ} \mathrm{C}$ for $15 \mathrm{~s}$ and $68^{\circ} \mathrm{C}$ for $1 \mathrm{~min} 10 \mathrm{~s}$. Since the species-specific probes were identical in nucleotide composition except for the SNP site, their melting temperatures were approximately the same.

A dilution series of $1: 1,1: 10,1: 100,1: 1,000$, and 1:10,000 representing 20,2, 0.2, 0.02 , and $0.002 \mathrm{ng}$ of DNA, respectively, was prepared in triplicate for two reference samples (one pure blood long-tailed macaque and one pure blood rhesus macaque) and a standard curve was then generated from averaged triplicate data points according to the above protocol. Absorbance readings at $260 \mathrm{~nm}$ were performed on a Qubit spectrophotometer (Invitrogen) for each sample. The original concentrations were used as a reference for subsequent dilution studies. The standard correlation coefficients were calculated using Pearson's correlation $\left(\mathrm{R}^{2}\right)$ [Evans et al., 2007].

\section{Results}

We have developed an inexpensive, quick, sensitive and accurate qPCR assay using primers that target a portion of the macaque Stat6 nuclear gene, and speciesspecific TaqMan probes that anneal specifically to either rhesus or long-tailed DNA 


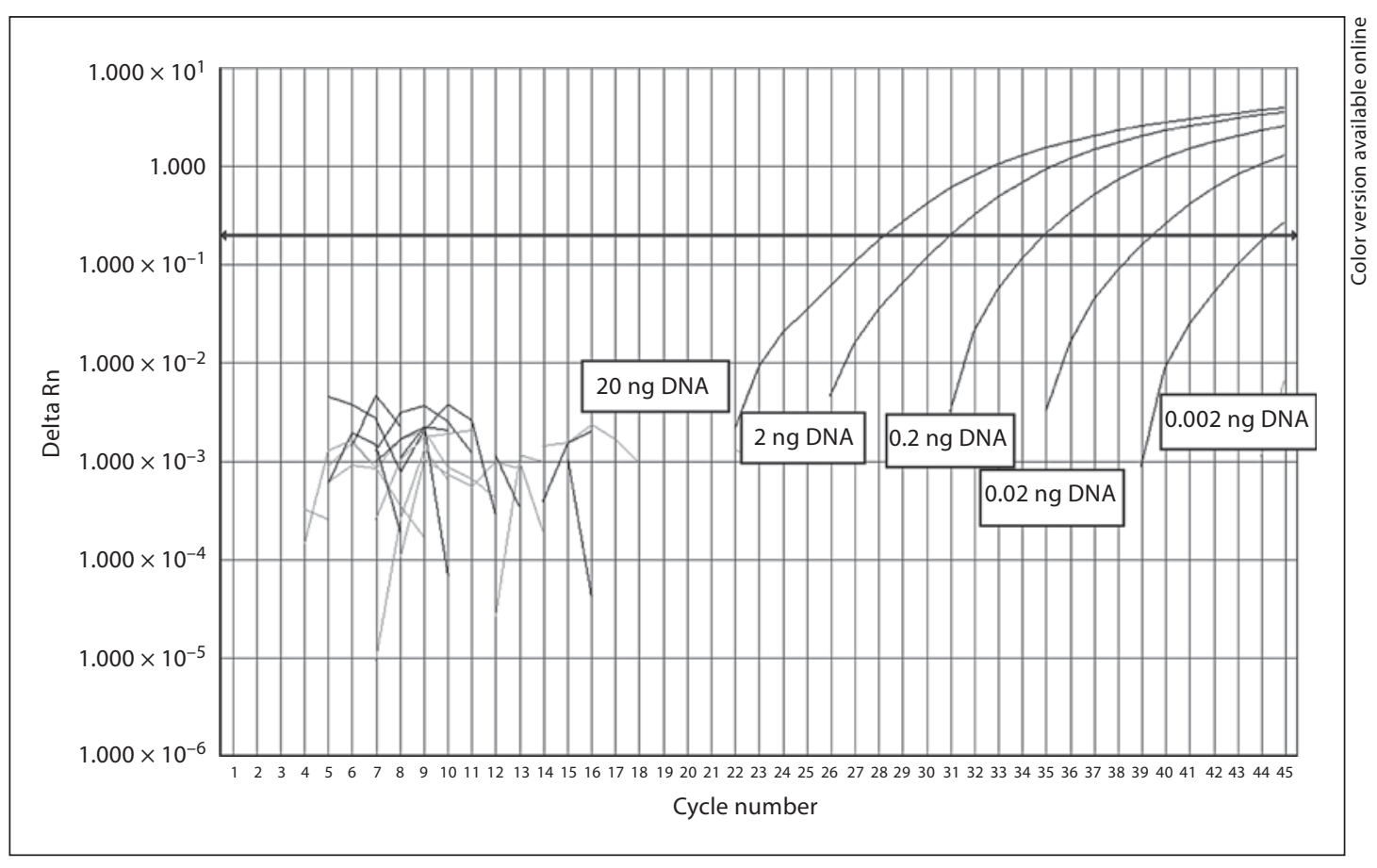

Fig. 3. qPCR amplification plot for a serial diluted $M$. fascicularis DNA sample (Zam12671). Each sigmoidal curve is a graphical depiction of fluorescence change (y-axis) as a function of PCR cycle number (x-axis). A threshold value was set (indicated by the horizontal line) during the log linear portion of amplification. Ct values [Evans et al., 2007] can be extrapolated from this threshold value. This is the initial point in the reaction when the increase in fluorescent signal is associated with exponential amplification of DNA. (Further details for each reaction are available on request.)

in this region. This duplex assay enabled quantification and species assignment of rhesus and long-tailed macaque DNA samples. The genotypes for the Stat6 SNP locus at base pair 491 were evaluated. Rhesus macaques possessed an A allele at this locus on both homologous chromosomes, i.e., all rhesus macaques were AA homozygotes, while a priori confirmed pure blood long-tailed macaques were homozygous for the $\mathrm{G}$ allele. Appropriate probe detection was specific for all individuals except for 3 Vietnamese long-tailed samples that possessed both the $G$ and A alleles at base pair 491 (fig. 2). The long-tailed macaque probe annealed specifically to all longtailed macaque DNA samples and the rhesus probe annealed specifically to all rhesus macaque DNA samples. Each sample displayed the standard logarithmic qPCR curve, all of which showed a cycle threshold (Ct) value in the range of 25-29.

In order to exploit the species-determining capability of this single SNP, the qPCR elongation temperature of $68^{\circ} \mathrm{C}$ far exceeded the melting temperature of the TaqMan primers. This was done to ensure specific probe binding. Interpretation of the data is simple and informative. Ct value data for the 1:1 to 1:10,000 triplicate dilution series were collected (for simplicity, fig. 3 shows a single amplification curve 
Table 2. Duplex qPCR data for M. fascicularis DNA sample (Zam12671)

\begin{tabular}{|c|c|c|c|}
\hline Sample name & $\begin{array}{l}\text { DNA concen- } \\
\text { tration, ng }\end{array}$ & Detector & Ct value \\
\hline Zam12671 1:1 & 20 & long-tailed & 28.2349 \\
\hline Zam12671 1:1 & 20 & rhesus & undetected \\
\hline Zam12671 1:10 & 2 & long-tailed & 31.0102 \\
\hline Zam12671 1:10 & 2 & rhesus & undetected \\
\hline Zam12671 1:100 & 0.2 & long-tailed & 34.9013 \\
\hline Zam12671 1:100 & 0.2 & rhesus & undetected \\
\hline Zam12671 1:1,000 & 0.02 & long-tailed & 39.4032 \\
\hline Zam12671 1:1,000 & 0.02 & rhesus & undetected \\
\hline Zam12671 1:10,000 & 0.002 & long-tailed & 44.2496 \\
\hline Zam12671 1:10,000 & 0.002 & rhesus & undetected \\
\hline
\end{tabular}

Duplex qPCR data for a M. fascicularis DNA sample (Zam12671) indicating long-tailed macaque probe binding and fluorescence detection. Ct values for serially diluted DNA are within the range of 28-44. The rhesus probe fluorescence was not detected with any long-tailed sample; the reverse was true as well.

for each concentration). $\mathrm{R}^{2}$ values of 0.996 and 0.982 were obtained for the rhesus and the long-tailed reference samples, respectively. The $\mathrm{R}^{2}$ values were derived from serial dilution values for log DNA concentration versus average Ct for each set of triplicate reactions. The resulting qPCR assay is robust and specific (table 2) and generates real-time data from DNA with concentrations as low as 2 pg of rhesus and long-tailed macaque genomic DNA.

\section{Discussion}

The sample of 109 rhesus and long-tailed macaques originating from different geographic locales in South, Southeast and East Asia provides an ideal resource to establish the level of intraspecies and interspecies variation at base pair 491 of the macaque Stat6 locus. Knowledge of this variation is essential to develop a robust species-testing assay.

Probe detection was specific for the presumed species except for 3 Vietnamese long-tailed samples that were assumed to be hybrids possessing both the $\mathrm{G}$ and $\mathrm{A}$ alleles at base pair 491 (fig. 2). The discovery of these hybrid animals using the assay is not surprising. Tosi et al. [2002] reported that rhesus male-mediated gene flow still persists in the zone of hybridization in Indochina. Kanthaswamy et al. [2010] have argued that the hybrid zone between rhesus and long-tailed macaques is not as narrow as the proposed zone of hybridization [Tosi et al., 2002]. The SNP composition of long-tailed macaques from Vietnam and rhesus macaques from western China suggests that the spatial pattern of admixture extends beyond northern Indochina eastwards into the range of rhesus macaques in eastern China, westwards into the range of rhesus macaques in the Indian subcontinent, through Burma, and as far 
south into the range of long-tailed macaques as Peninsular Malaysia [Kanthaswamy et al., 2010]. Traces of extensive historic and present introgression among the mainland populations of rhesus and long-tailed macaques persist in the domestic supply of primate products and research facilities in the US [Kanthaswamy et al., 2010]. Kanthaswamy et al. [2008] used STR genotypes to calculate the migration rates between the 2 macaque species within the purported hybrid zone. SNP information across the rhesus and long-tailed genomes revealed the geographic extent of interspecific admixture between Chinese rhesus and mainland long-tailed macaques [Kanthaswamy et al., 2010], and alleles in common in long-tailed macaques and Chinese rhesus populations are not random in distribution relative to the geographic distance among these populations but reflect a clinical variation.

Accurate quantification of the target DNA for these types of samples is crucial to the success of effective experimental analysis [Evans et al., 2007]. Even at levels of 2 pg of DNA, the Stat6 SNP qPCR assay permits interspecies identification with a clear and unequivocal separation between the rhesus macaque and the long-tailed macaque (fig. 3). This is especially useful for non-invasively collected, often degraded samples.

This stand-alone qPCR duplex assay is not only sensitive enough to correctly detect species-specific DNA, even at low sample concentrations, i.e., 2 pg DNA, but it can also be easily integrated into emerging SNP-based assays that are being developed for rhesus and long-tailed genetic studies [Kanthaswamy et al., 2010]. Most SNP- and STR-based assays that are used to estimate ancestry proportions of individual animals, even those using Bayesian clustering algorithms [Satkoski et al., 2008; Kanthaswamy et al., 2010], are not accurate unless an unrealistic number of ancestry-informative loci are employed, and there are no procedures to prove if ancestry estimates are accurate unless researchers have parallel information on every single ancestor of a study subject and their genetic composition. The interrogation of a SNP at base pair 491 of the Stat 6 locus by the assay will provide a result in the affirmative or negative whether a sample was derived from a pure blood rhesus or long-tailed macaque. Therefore, the assay has proved sufficient to differentiate rhesus and long-tailed macaque samples, and is also able to detect first-generation hybrid animals.

The bulk of long-tailed macaque samples imported into the United States is collected from macaques that inhabit the active hybrid zone in Southeast Asia that includes Vietnam, Cambodia, Laos, and Burma. The study suggests that not all rhesus and long-tailed samples should be treated equally in individual studies. The present study is consistent with earlier reports of the introgression of rhesus genes into longtailed macaques in Indochina. To ensure a consistent and reliable experimental model, the ability of biomedical researchers and primatologists, colony managers and conservationists to detect hybrid samples is critical.

\section{Acknowledgments}

We are grateful to all the following facilities that have contributed samples used in this study: Wisconsin National Primate Research Center, California National Primate Research Center, Primate Products, Inc., Covance, Inc., Tulane National Primate Research Center, University of Miami Perrine Primate Center and New Iberia Research Center. This study was supported by National Institutes of Health grants R24RR05090 and R24RR025871 to D.G.S. and National Institute of Justice grant 2008-DN-BX-K288 to S.K. 


\section{References}

AESOP Project (2006). Trends in US primate importation for 11 years (1995-2005) compiled and analyzed from live primate import declarations logged by the United States Fish and Wildlife Service's LEMIS division. http://www.aesopproject.org/Primate_Trade_Imports.htm.

Bonhomme M, Cuartero S, et al. (2009). Assessing natural introgression in 2 biomedical model species, the rhesus macaque (Macaca mulatta) and the long-tailed macaque (Macaca fascicularis). Journal of Heredity 100: 158-169.

Degenhardt JD, de Candia P, et al. (2009). Copy number variation of CCL3-like genes affects rate of progression to simian-AIDS in Rhesus Macaques (Macaca mulatta). PLoS Genet 5: e1000346.

Evans JJ, Wictum EJ, et al. (2007). Real-time polymerase chain reaction quantification of canine DNA. Journal of Forensic Sciences 52: 93-96.

Falconer DS (1960). Introduction to Quantitative Genetics. New York, The Ronald Press Company.

Ferguson B, Street SL, et al. (2007). Single nucleotide polymorphisms (SNPs) distinguish Indian-origin and Chinese-origin rhesus macaques (Macaca mulatta). BMC Genomics 8: 43.

Fooden J (1995). Systematic review of Southeast Asian longtail macaques, Macaca fascicularis (Raffles 1821). Fieldiana Zoology 81: 1-206.

Fooden J (2000). Systematic review of the rhesus macaque, Macaca mulatta (Zimmermann, 1780). Fieldiana Zoology New Series 96: 90-120.

Gibbs R, Rogers J, et al. (2007). Evolutionary and biomedical insights from the rhesus macaque genome. Science 316: 222-234.

Hajibabaei M, Singer GA, et al. (2007). DNA barcoding: how it complements taxonomy, molecular phylogenetics and population genetics. Trends Genetics 23: 167-172.

Hamada Y, Urasopon N, et al. (2006). Body size and proportions and pelage color of free-ranging $\mathrm{Ma}$ caca mulatta from a zone of hybridization in Northeastern Thailand. International Journal of Primatology 27: 497-513.

Hernandez RD, Hubisz MJ, et al. (2007). Demographic histories and patterns of linkage disequilibrium in Chinese and Indian rhesus macaques. Science 316: 240-243.

Hou J, Schindler U, et al. (1994). An interleukin-4-induced transcription factor: IL-4 Stat. Science 265: 1701-1706.

Kanthaswamy S, Smith DG (2004). Effects of geographic origin on captive Macaca mulatta mitochondrial DNA variation. Comparative Medicine 54: 193-201.

Kanthaswamy S, Satkoski J, et al. (2008). Interspecies hybridization and the stratification of nuclear genetic variation of rhesus macaques (Macaca mulatta) and long-tailed macaques (Macaca fascucularis). International Journal of Primatology 29: 1295-1311.

Kanthaswamy S, Satkoski J, et al. (2010). Detecting signatures of inter-regional and inter-specific hybridization among the Chinese rhesus macaque specific pathogen-free (SPF) population using single nucleotide polymorphic (SNP) markers. Journal of Medical Primatology 39: 252-265.

Leek JP, Hamlin PJ, et al. (1997). Assignment of the Stat6 gene (Stat6) to human chromosome band $12 \mathrm{q} 13$ by in situ hybridization. Cytogenetics and Cell Genetics 79: 208-209.

Malaivijitnond S, Sae-Low W, et al. (2008). The human-ABO blood groups of free-ranging long-tailed macaques (Macaca fascicularis) and parapatric rhesus macaques (M. mulatta) in Thailand. Journal of Medical Primatology 37: 31-37.

Satkoski J, George D, et al. (2008). Genetic characterization of wild and captive rhesus macaques in China. Journal of Medical Primatology 37: 67-80.

Smith DG, McDonough J (2005). Mitochondrial DNA variation in Chinese and Indian rhesus macaques (Macaca mulatta). American Journal of Primatology 65: 1-25.

Smith DG, George D, et al. (2006). Identification of country of origin and admixture between Indian and Chinese rhesus macaques. International Journal of Primatology 27: 881-898.

Tosi AJ, Coke CS (2007). Comparative phylogenetics offer new insights into the biogeographic history of Macaca fascicularis and the origin of the Mauritian macaques. Molecular Phylogenetics and Evolution 42: 498-504.

Tosi AJ, Morales JC, et al. (2002). Y-chromosome and mitochondrial markers in Macaca fascicularis indicate introgression with Indochinese M. mulatta and a biogeographic barrier in the Isthmus of Kra. International Journal of Primatology 23: 161-178.

Wurster AL, Rodgers VL, et al. (2002). Interleukin-4-mediated protection of primary B cells from apoptosis through Stat6-dependent up-regulation of Bcl-xL. Journal of Biological Chemistry 277: $27169-27175$. 